\title{
Can follow-up reminders from postal questionnaires help determine the mechanism of missing data in trials?
}

\author{
Ivana Holloway ${ }^{1 *}$, Amanda Farrin ${ }^{1}$, Anne Forster ${ }^{2}$, TRACS and LoTS Care teams ${ }^{1,2}$ \\ From 2nd Clinical Trials Methodology Conference: Methodology Matters \\ Edinburgh, UK. 18-19 November 2013
}

The issue of missing data is present in every trial. Identification of the missing data mechanism is not straightforward; however it is essential to avoid bias. The mechanism of missing completely at random (MCAR) is seldom appropriate and the distinction between missing at random (MAR) and not at random (MNAR) is not straightforward. Follow-up reminder responses provide excellent source of information for investigating the issue.

Improving postal response rates for patient-reported outcome measures often requires some kind of reminder process. Patient-reported outcomes from two stroke rehabilitation cluster randomised trials were used to investigate the usefulness of reminders in the identification of the missing data mechanism. In both trials, the reminder process was set-up from the outset. Missing data in these trials had an intermittent pattern. An approach by Fairclough (2010) was used to determine missingness mechanism.

Covariates predicting non-response (from reminderresponders) were first identified to distinguish between MCAR and MAR mechanisms and participants outcome scores were added to model testing for inclusion to check for evidence of MNAR.

The advantage of this method is that reminderresponses are considered to be similar to non-responders with the additional benefit of knowing the actual outcome. Furthermore, identification of covariates indicated by this approach can inform the choice of covariates for the appropriate method of data imputation.

In trials with potentially high loss to follow-up, reminder strategies can be used not only to minimise loss to

'University of Leeds, Leeds, UK

Full list of author information is available at the end of the article follow-up but offer valuable data to examine mechanisms of missingness and ultimately contribute to a robust final analysis.

Authors' details

'University of Leeds, Leeds, UK. ${ }^{2}$ Bradford Institute for Health Research, Bradford, UK.

Published: 29 November 2013

doi:10.1186/1745-6215-14-S1-P108

Cite this article as: Holloway et al.: Can follow-up reminders from postal questionnaires help determine the mechanism of missing data in trials? Trials 2013 14(Suppl 1):P108.

Submit your next manuscript to BioMed Central and take full advantage of:

- Convenient online submission

- Thorough peer review

- No space constraints or color figure charges

- Immediate publication on acceptance

- Inclusion in PubMed, CAS, Scopus and Google Scholar

- Research which is freely available for redistribution

Submit your manuscript at www.biomedcentral.com/submit
() Biomed Central

\section{Biomed Central}

(c) 2013 Holloway et al; licensee BioMed Central Ltd. This is an Open Access article distributed under the terms of the Creative Commons Attribution License (http://creativecommons.org/licenses/by/2.0), which permits unrestricted use, distribution, and reproduction in any medium, provided the original work is properly cited. 